\title{
A Psycholinguistic Investigation into Diminutive Strategies in the East Franconian NP: Little Schnitzels Stay Big, but Little Crooks Become Nicer
}

\author{
Eva Wittenberg \\ Central European University \\ Andreas Trotzke \\ University of Konstanz
}

\begin{abstract}
Upper German dialects make heavy use of diminutive strategies, but little is known about the actual conceptual effects of those devices. This paper is the first to present two large-scale psycholinguistic experiments that investigate this issue in East Franconian, a dialect spoken in Bavaria. Franconian uses both the diminutive suffix -la and the quantifying construction $a$ weng $a$ lit. 'a little bit a' to modify noun phrases. Our first experiment shows that diminutization has no effect on conceptualization of magnitude: People do not think of a smaller/weaker/shorter etc. referent when the NP is modified by the morphological diminutive, the quantifying construction, or their combination. The second experiment involves gradable NPs and shows that, again, the morphological diminutive has no effect on how people conceptualize the degree to which a gradable nominal predicate holds; in contrast, $a$ weng $a$ reduces it significantly. These experiments suggest that diminutization does not have uniform effects across semantic domains, and our results act as a successful example of extending the avenue of cognitive psychology into dialectology with the active participation of a speaker community.*
\end{abstract}

\footnotetext{
* We first and foremost thank all our participants in Upper Franconia. We also thank the radio stations Euroherz, Bayerischer Rundfunk Franken, and extraradio, as well as the newspaper Frankenpost for distributing the links to our experiments and encouraging participation and engagement. We also thank Mohit Gurumukhani and Phillip Lagoc for help with programming, as well as the audiences at ICLaVE|10 in Leeuwarden and at the 14. Bayerisch-Österreichische Dialektologentagung in Salzburg for helpful feedback and discussion. Andreas Trotzke gratefully acknowledges financial support from the EU Horizon 2020 COFUND scheme (grant no. 2017-BP00031)

(C) Society for Germanic Linguistics 2021. This is an Open Access article, distributed under the terms of the Creative Commons Attribution license (http://creativecommons.org/licenses/by/4.0/), which permits unrestricted reuse, distribution, and reproduction in any medium, provided the original work is properly cited.
} 
Keywords: degree, diminutive, East Franconian, magnitude, measurement, noun phrase

\section{Introduction.}

It is often mentioned in the literature that the highly frequent use of diminutive strategies is a signature property of several Upper German dialects (see Kargl 1976 on Bavarian; Siebenhaar \& Wyler 1997 on Swiss German; and Schirmunski 1962, Dressler \& Barbaresi 1994 for a general overview). In this paper, we focus on East Franconian and explore the extent to which this frequent use corresponds to semantic bleaching and whether or not different diminutive strategies differ in this regard. East Franconian is an Upper German dialect spoken mainly in the northeastern region of Bavaria by about 4.9 million speakers (Eberhard et al. 2015).

We investigate these questions by restricting ourselves to two relevant strategies in this particular variety: the diminutive suffix -la and the quantifying construction $a$ weng $a$. Our hypothesis is that these two devices can potentially function to measure both the magnitude of noun referents and, in the case of gradable noun phrases, the degree to which a predicate holds.

Our paper is structured as follows. In section 2, we first introduce the two different diminutive strategies we are focusing on, and we motivate our driving premise that these devices can profitably be compared with each other because in East Franconian they feature the same basic constraint when occurring with noun phrases: Both turn mass nouns into count nouns. However, we argue that the two diminutive devices modify the noun referent at two different structural levels: - $l a$ is a numeral classifier inside the noun phrase (section 2.1), whereas $a$ weng $a$ is a quantifying construction that operates at the level of the determiner phrase (section 2.2).

After having characterized these core conceptual and structural properties of the different diminutive strategies, we propose two possible hypotheses regarding their measurement function in section 2.3: Either those diminutive devices can measure the magnitude (that is, the size) of the noun referent, or they can measure the degree of predicates that we find in gradable nouns, or they can function in both conceptual domains of measurement. Section 3 then reports on our first experiment. In this phrase-picture matching study, we tested the extent to which the two diminutive strategies and their combination (as in a weng a bia-la 'a little a beer-DIM') function as a means to indicate magnitude and thus diminish 
the size of the respective noun referents. Foreshadowing the results, we find no effect of either diminutive strategy on magnitude conceptualization. In section 4, we then present our second experiment, where we asked whether or not either -la or $a$ weng $a$ or a combination of the two can reduce the degree to which to which a predicate holds in gradable noun phrases. In order to explore this question, we conducted a rating task where the different diminutive strategies occurred with gradable nouns. Indeed, we find that the quantifying construction $a$ weng $a$ reduces the degree to which a predicate holds, in contrast to the semantically bleached morphological diminutive -la. Section 5 summarizes our results and concludes with a discussion of potential theoretical and empirical implications of the psycholinguistic approach to dialectal phenomena illustrated in our paper.

\section{Diminutive Strategies in East Franconian.}

Each language slices up the space of diminutization differently, using syntax, the lexicon, and morphology, but little is known about how much each grammatical device contributes to how people conceptualize a referent. In what follows, we focus on a morphological diminutive, a complex quantifying construction, and on the types of nouns both devices can syntactically be combined with.

\subsection{The Diminutive Suffix -la.}

Let us first illustrate the morphological diminutive, which is realized by the suffix -la in East Franconian. It is well known that diminutive marking in Standard German turns mass nouns into count nouns. The same holds for Upper German versions of Standard German -chen in 1b, such as East Franconian $-l a$ in $2 b$.

(1) a. viel Wein

much wine

b. zwei Wein-chen

two wine-DIM

'two glasses of wine'

(2) a. vill Bia

much beer 
b. zwaa Bia-la

two beer-DIM

'two glasses of beer'

As soon as the diminutive suffixes -chen and -la are present, as in $1 \mathrm{~b}$ and $2 \mathrm{~b}$, respectively, the noun must be interpreted as a count noun (Jurafsky 1996). In what follows, we capitalize on this central fact and abstract away from further semantic and/or pragmatic functions that the diminutive might have. Intuitively, at least in Standard German, the diminutive shrinks the size of its noun referent, but here we start with the assumption that this additional meaning component might vary from language to language, and from variety to variety. We hypothesize that in Upper German dialects such as East Franconian, the high frequency of the use of diminutive forms might actually correspond to semantic bleaching (for further semantic/pragmatic effects of diminutives from a crosslinguistic perspective, see Fortin 2011, Parzuchowski et al. 2016, and our discussion in section 5 below). ${ }^{1}$

Accordingly, as soon as one focuses only on the productive pattern of diminutive marking on mass nouns, it becomes clear that diminutives can be analyzed along the lines of other numeral classifiers such as Glas 'glass' in so-called "counting constructions" (Wiese \& Maling 2005):

(3) zwei Glas Bier

two glass beer

'two glasses of beer' (count reading only)

Since numeral classifiers such as Glas share this basic semantic feature of turning mass into count nouns, many syntactic analyses treat them as similar and propose structural analyses such as in 4 in order to account for this parallel (see Wiltschko 2006, Ott 2011, and many others). The

\footnotetext{
${ }^{1}$ Note that we use the term semantic bleaching in the sense of Jurafsky 1996 as simply indicating that an expression can have a more abstract and vague meaning, in addition to or instead of its core semantics; in our paper, we primarily understand it from a synchronic perspective as relevant to present-day speakers, since we cannot make any claims as to what brought it about (and a discussion of the vast historical literature on this topic would take us too far afield; see Hopper \& Traugott 2003 for a usage-based approach and Roberts 2010 for a generative approach to bleaching).
} 
category $n$ is the "light noun"- a category that has been used for a variety of phenomena at the syntax-morphology interface (Marantz 1997), and especially for classifier systems of East Asian languages (for example, Kishimoto 2000, Hiraiwa 2016, 2018). ${ }^{2}$
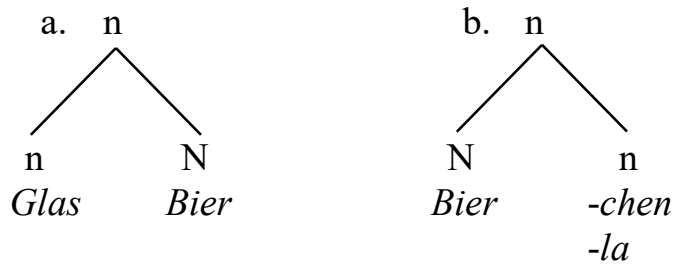

In 4, diminutive suffixes, along with further numeral classifiers, can thus be analyzed as light nouns. This approach is in line with an insight that the only semantic effect of the morphological diminutive that seems to hold across languages and varieties is that it specifies a countable entity of the concept expressed by a noun (as in das Bier ${ }_{\text {MASS }} \rightarrow$ das Bier-chen COUNT; Bale \& Barner 2018), which then also could be pluralized (as in die Bierchen $_{\text {COUNT }}$ ). This process can be modeled either using the exoskeletal approach outlined in 4, analyzed within the level of semantics through a process of lambda abstraction, as proposed by Jurafsky (1996), or through a process of morphological composition that signals a conceptual effect (Wiese 2006).

Under either account, the smallest common denominator of nominal diminutives is that they refer to something like "one piece of N" at the conceptual level, and it remains to be seen whether or not diminutive suffixes also have interpretive effects beyond this basic component of conceptualization - for instance, by additionally modifying the size of the noun referent (that is, one small piece of $N$; for example, Schneider 2013). Before investigating this question in more detail in sections 3 and 4 below, let us first turn to another diminutive strategy in East Franconian whose distribution with mass versus count nouns follows a similar pattern and

\footnotetext{
${ }^{2}$ Nothing in our paper hinges on the particular theoretical framework one assumes; we formulate these analyses to be understandable to a wide readership, but theories assuming different mapping mechanisms between syntax and semantics would not make different predictions as far as we are aware. See also section 5 for discussion.
} 
can thus be profitably compared with diminutive suffixes: the quantifying construction $a$ weng $a \mathrm{~N}$.

\subsection{The Quantifying Construction a Weng a.}

The quantifier weng is the East Franconian version of Standard German wenig 'few, little'. Interestingly, this quantifier can occur in a construction with indefinite determiner doubling, as in 5 , which is a signature property of Upper German dialects, especially of Bavarian (Brandner 2008, Kallulli \& Rothmayr 2008, Leu 2008, 2015).

(5) a weng a Bia

a little a beer

'a small glass/portion of beer' (count reading only)

As already pointed out in the literature, the doubling of definite determiners in Upper German varieties is restricted. That is, it can only occur with a certain set of lexical elements such as ganz 'very, completely'. An example would be the following Austro-Bavarian case from Kallulli \& Rothmayr 2008:101 in 6a. However, it has also been noted, in the very same literature, that there are differences in acceptability between Upper German varieties in Austria and Germany, and, according to our judgment, the corresponding example in $6 \mathrm{~b}$ is not possible in East Franconian.

(6) a. Ees seids de ganz de Gscheidn. you are the very the clever

b. ??Iah seid die ganz die Gscheidn. you are the very the clever

'You are the very clever/the cleverest ones.'

Although judgments may thus vary regarding doubling of the definite determiner as such, it is undisputed that co-occurrence of the definite determiner with weng is only possible when the latter functions as a quantifier under the mass-noun reading of the noun referent, as in $7 \mathrm{a}$; the doubling of definite determiners with weng is ungrammatical, as in $7 \mathrm{~b}, \mathrm{c}$ 
(7) a. des weng bia

the little beer

'the small quantity of beer' (mass reading only)

b. *des weng des bia the little the beer

c. *a weng des bia $^{3}$

a little the beer

We thus conclude that doubling of a determiner in East Franconian in a construction that also contains weng is only possible with the indefinite determiner (see 5 above). Focusing on indefinite determiner configurations, we now observe that without doubling of the indefinite determiner, weng can again only occur with mass nouns:

(8) a weng Bia

a little bia

'a small quantity of beer' (mass reading only)

Given our discussion in section 2.1, this predicts that indefinite determiner doubling + weng should also be acceptable with the diminutive suffix -la because this suffix can also only occur under the count-noun reading. In other words, we predict that the quantifying construction $a$ weng $a$ should be acceptable with the diminutive suffix, and this is indeed what we observe:

(9) a weng a Bia-la

a little a bia-DIM

'a small glass/portion of beer' (count reading only)

${ }^{3}$ The combination of $a$ weng with a definite determiner is only possible in an adverbial position, modifying the verb, as in $\mathrm{i}$.

(i) Dringg amoll a weng des bia aus.

drink.IMP PART a little the beer out

'Finish the beer ( $\approx$ quickly)' 
Following the data patterns above, we thus conclude that the quantifying construction $a$ weng $a$ crucially depends on doubling of the indefinite determiner. That construction can optionally co-occur with diminutive morphology on the noun because this morphology is subject to the same constraint of having to occur with count nouns. Based on the examples above, we propose the following basic structure of the quantifying construction $a$ weng $a$, which corresponds to structural claims that have been made for Bavarian indefinite determiner doubling (Kallulli \& Rothmayr 2008). In particular, we postulate that the doubling can be analyzed as a recursive DP structure, and we analyze weng as head of a Q(uantifier) Phrase:

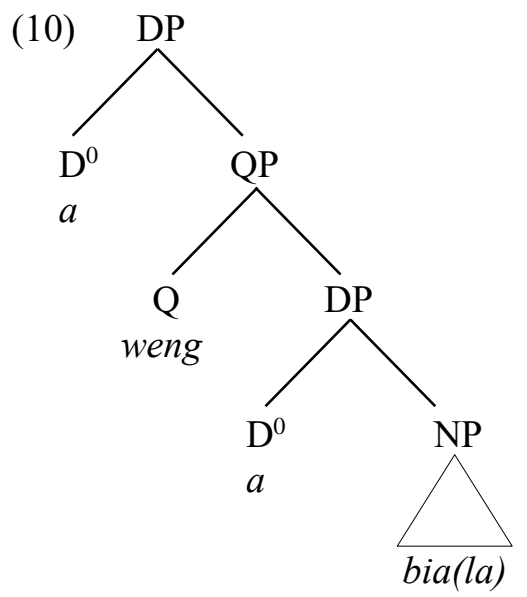

Let us briefly summarize the East Franconian data we have introduced so far: In section 2.1, we showed that the diminutive suffix -la turns mass nouns into count nouns and thus has the same interpretive effect as numeral classifiers. Section 2.2 has introduced the quantifying construction $a$ weng $a$, and we demonstrated that this linguistic device likewise turns mass nouns into count nouns and that, under the count reading, the quantifier weng can only occur with doubling of the indefinite determiner. Based on these distributional patterns, we now turn to the questions that motivated our comparison of these two linguistic devices and thus our experimental investigations of diminutive strategies in the East Franconian noun phrase. 


\subsection{Functions of East Franconian Diminutive Strategies: Two Hypotheses.} Given the observations in sections 2.1 and 2.2, we now move on to explore a question already hinted at above: Do these East Franconian elements have a function that goes beyond their conceptualizing role of turning mass into count nouns? We submit that there are at least two such potential functions that suggest themselves. First, following the classical analysis of diminutives as a device that "means at least 'small" (Jurafsky 1996:534, and table 1; Schneider 2013), both the diminutive suffix -la and the quantifying construction $a$ weng $a$ could additionally be interpreted as signals that the size of the noun referent is diminished. If this is true, then they function as modifiers in the conceptual domain of magnitude. Note that intuitively this function is always associated with the diminutive suffix, but it is unclear whether or not East Franconian diminutives fulfill this function: The sheer frequency of diminutives in this variety of German may correspond to semantic bleaching (on Upper German diminutives in particular, see Kolmer 1999, and earlier Schiepek 1908).

A second way in which both the suffix -la and the construction $a$ weng $a$ could have a diminishing function is not within the domain of magnitude (size, volume, length, etc.), but within the domain of degrees of gradable noun phrases. That is, in addition to testing whether or not these diminutive devices play a role in measuring magnitudes of objects, we also consider the possibility that they could function in the domain of measuring degrees of predicates. This hypothesis is driven by the observation in the literature that examples such as 11 have, in fact, two interpretations (example from Kolmer 1999:34).

\section{(11) a weng a schlechts Bia}

a little a bad beer

'a small glass/portion of bad beer' or 'a slightly bad beer'

First, 11 can refer to a small portion of bad beer; second, it can refer to the small degree to which the substance beer has gone bad. Accordingly, we observe that $a$ weng $a$ can also modify the degree of predicates such as the adjective schlechts 'bad' in 11. In order to enable the comparison between the diminutive morpheme -la and $a$ weng $a$ (based on their common syntactic distribution with count nouns), we focus on gradable nouns instead, and not on adjective-noun combinations. Consider the following examples, showing that some nouns denote gradable properties, as in 12a, 
while others do not, as in 12b (see Morzycki 2009 for extensive discussion of this difference).

(12) a. ein großer Idiot

a big idiot

b. a großer Junge

a big boy

Since the noun idiot in 12a denotes a gradable predicate and thus has the degree reading 'someone who is idiotic', its combination with an adjective such as big most likely results in the reading that someone is idiotic to a high degree. In other words, the adjective does not measure the physical size of someone who is an idiot, but rather modifies the degree component of the gradable noun idiot. In contrast, nouns such as boy in $12 \mathrm{~b}$ do not have such a degree reading and thus their combination with big most likely yields the reading 'someone who is a boy and who is big for a boy'. Accordingly, nouns such as idiot may be thought of as containing an abstract degree head POS, which distinguishes them from nongradable cases and heads the Deg(gree) Phrase (see Kennedy \& McNally 2005 on POS and Morzycki 2009:188 on the following structural claim, and Morzycki 2016:157-162 on Deg Phrases more generally). In 13, $e$ is the type of entities/individuals, $t$ is the type of truth values, and $d$ refers to degree.

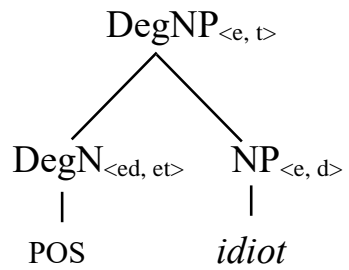

Semantically, we would expect $a$ weng $a$ to have an effect on degree modification, because of weng's usual function as a mass noun modifier, indicating the quantity of a substance, as in (8). To see this, consider the conceptual parallels between the measurement of mass nouns and predicates denoting degrees. For instance, if a mass, such as 'beer', is divided, it stays beer; if a degree predicate such as being an idiot is reduced, the person still stays an idiot - whereas if one divides a count 
object such as 'cup', the resulting parts are not still 'a cup'. This has been called the principle of divisiveness in the literature (Bale \& Barner 2009; Wellwood 2015; Wittenberg \& Levy 2017).

We suggest that in order to explore the conceptual effects of diminutive strategies, one therefore should consider also this degree component of gradable nouns, in addition to their effect on measuring (physical) sizes. Accordingly, complementing our study on magnitude effects described in section 3 below, we also conducted an experiment where we tested the co-occurrence of East Franconian gradable nouns (analogous cases to idiot above; for example, Gribbl 'crook') with both the diminutive suffix, the quantifying construction, and a combination of the two. However, let us first start with our experiment on potential magnitude effects.

\section{Experiment 1.}

Our first study investigated the effect of the morphological diminutive $l a$ and the quantifying construction $a$ weng $a$ on the magnitude semantics of nouns. As already mentioned in section 2 above, we hypothesize that the high frequency of the morphological diminutive -la corresponds to a semantic bleaching, which should surface as an absence of a diminutive effect on object magnitude. We also ask whether the quantifying construction a weng a may serve a diminutive function, since it has the same distribution as the morphological diminutive, insofar as it can only occur with count nouns.

\subsection{Participants, Methods, and Materials.}

We recruited 129 participants from Franconia through social media, through an interview of the first author to a local newspaper in Upper Franconia, and through local radio announcements. We excluded five participants because they indicated (by self-report) that they were not fluent speakers of East Franconian and/or avoided dialect whenever possible. The remaining 124 participants were on average 42 years old (range: $22-74$ ), and $52 \%$ of them were female.

We conducted an extensive dialect questionnaire, asking about dialect use frequency, language attitude, and proficiency. All our final participants had a positive attitude toward dialect, and reported to be proficient, using dialect often and for the most part deliberately. Figure 1 
shows the expected positive correlation between attitude and frequency of dialect use.

Dialect Use and Attitude

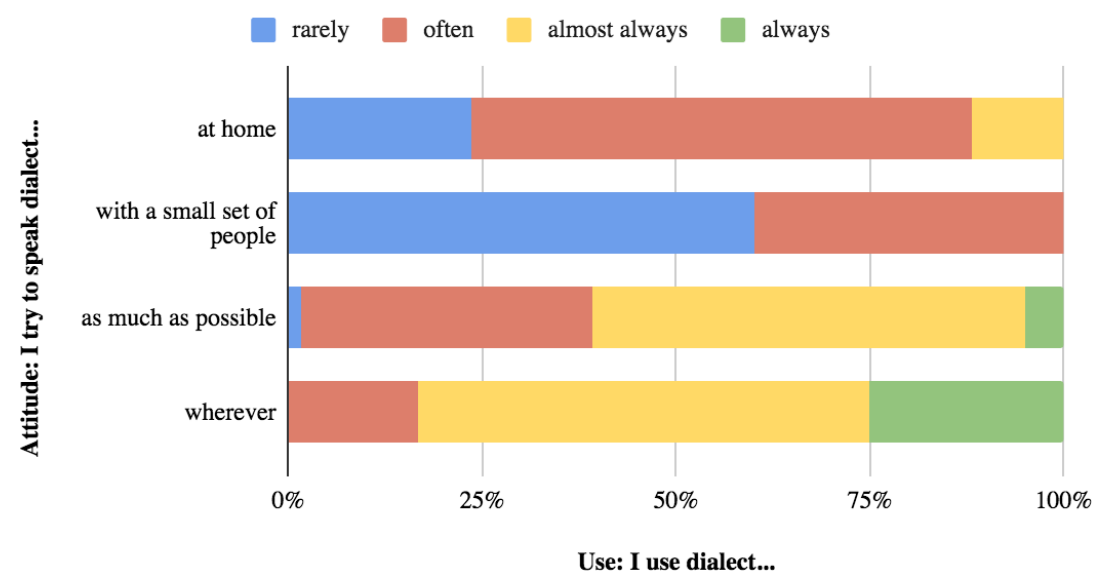

Figure 1. Dialect use and attitude of participants in experiment 1.

For the demographics questionnaire, we used the web-based survey platform Qualtrics (Qualtrics, Provo, UT), from which we directed visitors (with their consent) to the experiment. We hosted the experiment on the servers of the University of California, San Diego, using the jsPsych (Leeuw 2015) library with custom plug-ins to present this and the subsequent study and to record data.

Participants were presented with a cover story about having an elderly neighbor who records an audio tape in lieu of writing a shopping list when she goes to the supermarket. This was done in order to make the task more interactive and to avoid interference from orthographic forms in a dialect without a written norm. Participants were instructed to help their fictitious elderly neighbor to pick the appropriate object or objects from a shopping list. This list was recorded by the first author (a native speaker), and the audio files were spliced by research assistants such that half of the items were combined with the carrier phrase und dann breicherd ich nuch 'and then I'd also need...', and half of them were combined with und außerdem nuch 'and then also...'. 
There were 12 filler items varying according to number (singular versus plural) and mass versus count nouns. These served as distractor items to conceal the purpose of 16 critical items in four conditions: unmodified, as in $14 \mathrm{a}$, modified by the morphological diminutive -la, as in $14 \mathrm{~b}$, modified by both -la and the quantifying construction $a$ weng $a$, as in $14 \mathrm{c}$, and modified by $a$ weng $a$, as in $14 \mathrm{~d} .^{4}$

(14) a. ... dann hedd ich gern noch an epfl then like I PART also an apple

b. ... dann hedd ich gern noch a epfal-a then like I PART also an apple-DIM

c. ... dann hedd ich gern noch a weng a epfal-a then like I PART also a little an apple-DIM

d. ... dann hedd ich gern noch a weng an epfl then like I PART also a little an apple '...then, I'd also like an apple'

The presentation of trials was Latin-squared, such that each participant never heard a given expression more than once, but heard each modification option four times, in combination with four different nouns; the order of items was pseudorandomized. Participants selected the matching items from an array of pictures by clicking on the pictures themselves. For fillers, there were 3-6 pictures to choose from, all chosen to represent distractors or close semantic neighbors of the respective filler item (see https://osf.io/n82c5/, Experiment I, for pictures and audio recordings). Critical items were the same pictures in four different sizes. The sizes were created by taking a reference picture and by reducing its size by a quarter, half, and three-quarters (see figure 2 ).

${ }^{4}$ Notice that the pattern of the second article a/an illustrates the gender change into neuter commonly introduced by the morphological diminutive. Further note that the stimuli were created in adherance with prosodic preferences, which in East Franconian are primarily dactylic

(i) Baam 'tree' $\rightarrow$ ? Baam-la versus Baam $\rightarrow$ Baam-a-la

This is concordant with the long-recognized phonotactic and prosodic functions of diminutives (for further discussion, see Wiese 2006 and Edelhoff 2016). 


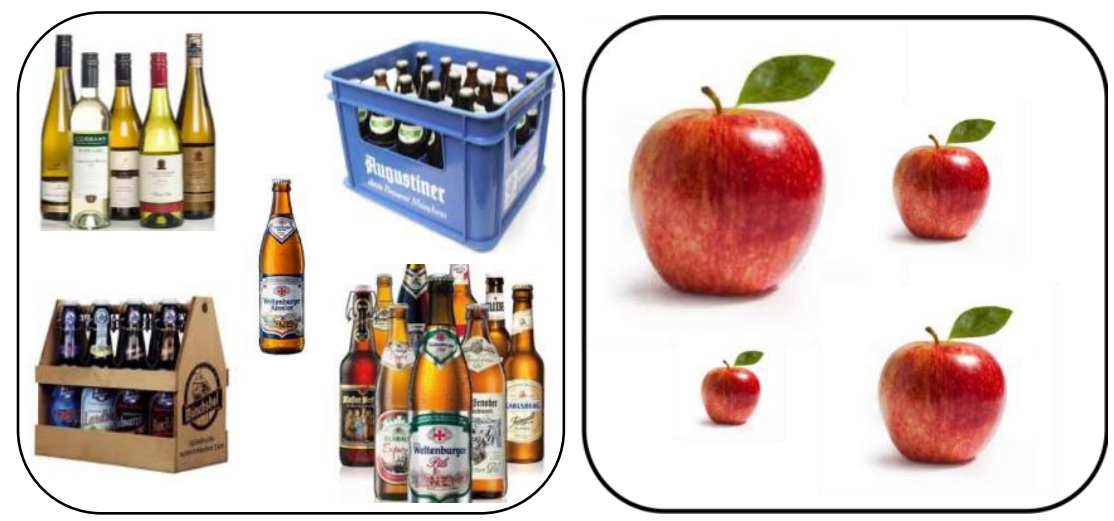

Figure 2. Example stimuli used in experiment 1 (filler on the left; critical item on the right).

The dependent variable was the size of the selected picture. If morphological diminutives are not bleached in East Franconian, sentences such as $14 \mathrm{~b}, \mathrm{c}$ should result in choices of smaller average sizes than sentences with nonmodified nouns, as in 14a. The same logic applies to the the quantifying construction $a$ weng $a$.

\subsection{Results and Discussion.}

Performance on filler items was at ceiling, with an overall accuracy rate of $94.7 \%$ (range: $77 \% \sim 100 \%$ ). The only filler item receiving less than $91 \%$ accuracy was a Flaschn Wein 'a bottle of wine', which some participants interpreted as plural, selecting a competitor picture that displayed multiple bottles of wine. The high accuracy rates on the filler items indicate that participants were taking the task seriously and had no trouble following the instructions.

We analyzed the data using a mixed-effects cumulative logit model, implemented by R's ordinal package (Christensen 2019): For ordered response categories (in our case, four bins ranging from smallest to biggest), this kind of model specifies response probabilities for a given choice of bin as a function of predictor variables - in our case, how the noun was modified. Instead of the intercept, ordered logit models provide a set of threshold parameters, which describe the boundaries from one bin to the next, and the probability of being drawn from one particular bin is 
estimated by the linear predictors with the inverse logit function (Wittenberg \& Levy 2017). Since model comparisons (Levy 2014) showed that none of the demographic factors explained a significant amount of the variance and including them did not change the pattern of the results, we only report the simplest model here, with only modifier as fixed predictor, and item and subject as random intercepts.

Table 1 contains an overview of the results of the cumulative logit model, which confirm this impression statistically. The first three rows indicate the threshold coefficients from one bin (smallest/small/big/ biggest) into the next. The regression coefficient $(\beta)$ for each modifier is shown in the next part, with "no modification" as a baseline: For instance, the value of -.16 for the quantifying construction would mean that $a$ weng $a+$ NPs are associated with smaller sizes. However, none of the predictors are significant: Neither diminutive option - the quantifying construction, the morphological diminutive, or their combination - had any effect on which size of objects people chose. 


\begin{tabular}{|c|c|c|c|}
\hline & $\beta$ & SE & \\
\hline \multirow{4}{*}{$\begin{array}{r}\text { smallest | small } \\
\text { small | big } \\
\text { big | biggest }\end{array}$} & -1.52 & 0.17 & \multirow[b]{4}{*}{$p$-value } \\
\hline & 0.01 & 0.16 & \\
\hline & 1.46 & 0.16 & \\
\hline & $\beta$ & SE & \\
\hline morphological diminutive $(-l a)$ & 0.14 & 0.16 & 0.41 n.s. \\
\hline quantifying construction ( $a$ weng $a$ ) & -0.16 & 0.16 & 0.32 n.s. \\
\hline \multirow[t]{2}{*}{ both $(a$ weng $a$ N-la) } & 0.11 & 0.16 & 0.49 n.s. \\
\hline & $\beta$ & $\mathrm{SE}$ & \\
\hline \begin{tabular}{l|l} 
smallest & small
\end{tabular} & -1.52 & 0.17 & \\
\hline \multirow{3}{*}{$\begin{array}{r}\text { small | big } \\
\text { big | biggest }\end{array}$} & 0.01 & 0.16 & \\
\hline & 1.46 & 0.16 & \\
\hline & $\beta$ & SE & $p$-value \\
\hline morphological diminutive $(-l a)$ & 0.14 & 0.16 & 0.41 n.s. \\
\hline quantifying construction ( $a$ weng $a$ ) & -0.16 & 0.16 & 0.32 n.s. \\
\hline both ( $a$ weng $a \mathrm{~N}-l a)$ & 0.11 & 0.16 & 0.49 n.s. \\
\hline
\end{tabular}

Table 1. Experiment 1: Regression table for categorizations (n.s. means "not significant").

Figure 3 shows, coded by color, the proportion of picture sizes chosen, depending on how the item was described - with the morphological diminutive -la, the quantifying construction $a$ weng $a$, both, or neither. As can be seen at first glance, most choices are close to or at chance level. 


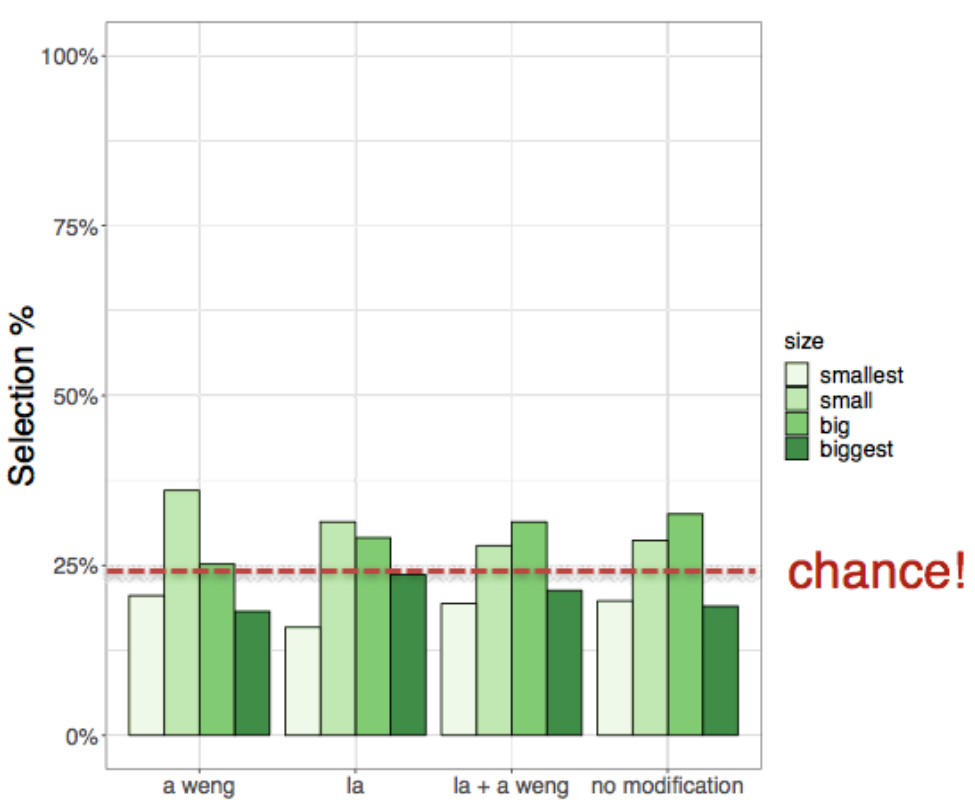

Figure 3. Experiment 1: Proportion of picture sizes chosen, per diminutization option.

This experiment asked two questions: We investigated whether the morphological diminutive -la and the quantifying construction $a$ weng $a$ affect how people conceptualize the magnitude of noun referents, using a phrase-picture matching task: Participants listened to a grocery list and clicked on the best candidate items from an array of pictures. The results show that indeed, people do not pick smaller referents out of an array if the referent is described using the morphological diminutive -la. This was expected, based on how frequently morphological diminutives are reported to be used in Upper German dialects, presumably resulting in a bleached-out function (see our discussion in section 2 above). However, the results also show that the quantifying construction $a$ weng $a$ likewise has no effect on how people decide on a referent for a noun. In sum, people picked the referent at chance level, regardless of whether a noun was modified by -la, a weng $a$, or even both -la and $a$ weng $a$.

However, as argued above, the function of both the morphological diminutive -la and that of the quantifying construction $a$ weng $a$ cannot only be analyzed in terms of magnitude, but also in terms of degree. In the 
second experiment, we ask whether these two ways of forming diminutives in East Franconian result in how people make degree judgments.

\section{Experiment 2.}

This study investigated the effect of the morphological diminutive -la and the quantifying construction $a$ weng $a$ on the degree semantics of gradable nouns. Based on the relevant literature mentioned in section 2, we note at least that $a$ weng $a$ could not only play a role in measuring magnitudes of objects, but that diminutive strategies more generally, and in particular $a$ weng $a$, also play a role in measuring degrees of predicates.

Since our aim was to compare the morphological device -la with the phrase-level modifier $a$ weng $a$, we used gradable nouns for our study instead of adjective-noun combinations, our assumption being that it would not be possible to investigate the role of the noun-attaching diminutive -la on degrees of predicates in a more complex adjective-noun construction. In other words, the path we chose allows for the most parallel comparison between morphological -la and $a$ weng $a$.

\subsection{Participants, Methods, and Materials.}

We recruited 109 participants through the same channels as in experiment 1. We excluded 1 participant because they indicated (by self-report) that they never speak East Franconian. The remaining 108 participants were between 20 and 81 years old (average age: 45 ), and 51\% of them were female. As in experiment 1, our participants' language attitude was quite positive, and their usage for the most part frequent. Figure 4 shows the participants' responses with respect to their dialect and language attitude. The heatmap (top) indicates the participants' dominant dialect. The bottom figure correlates participants' self-assessed frequency of dialect use and their willingness to use it if they were to be interviewed on national news ("Tagesschau") as an indication of language attitude. To host this experiment, including the demographics questionnaire, we only used the web-based survey platform Qualtrics (Qualtrics, Provo, UT). 


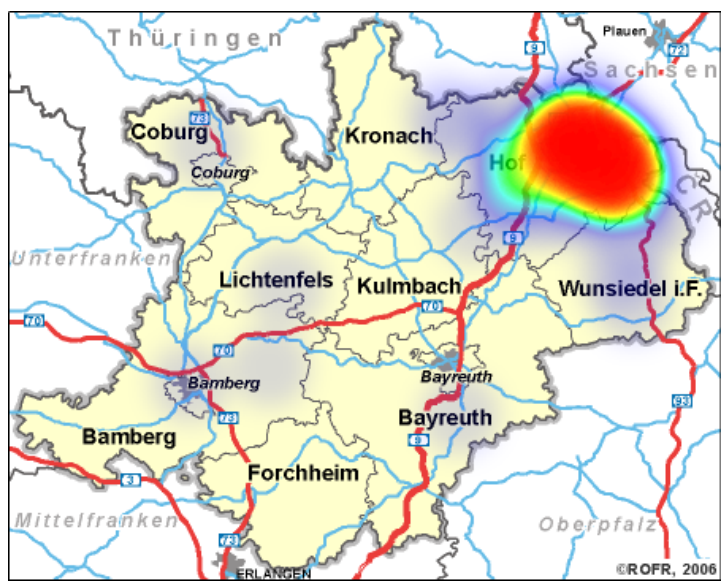

Would you use dialect on national news?

$100 \%$

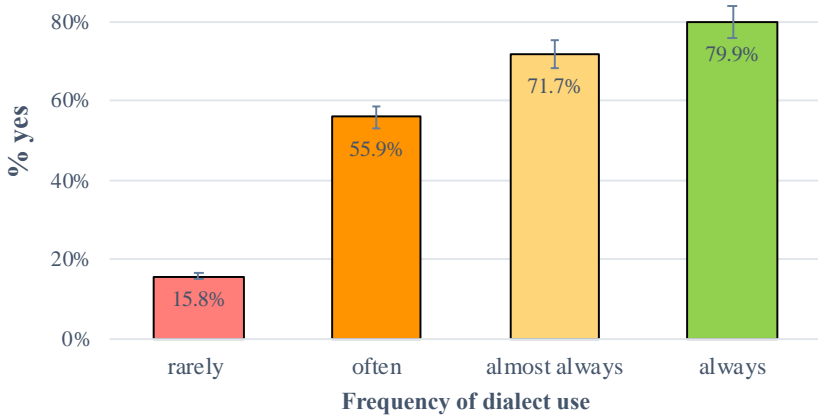

Figure 4. Participants' dominant dialect and attitude.

Participants were instructed to rate the degree to which a predicate holds in a gradable noun; that is, they assessed the "strength" of modified or unmodified nouns on a scale from 1 to 10 . As in experiment 1 , we created eight critical trials (as in 15a-d), and eight filler trials (for a full list of stimuli, see Supplemental Material). Both the nouns and the adjectives used in the evaluation task were taken from a local dialect dictionary (Müller 2013). As discussed in section 2 above, gradable nouns are often those that have clear evaluative concepts associated with them (see the prominent example idiot in Morzycki 2009); hence, we used mild invectives, such as Gribbl 'crook', Schlawiner 'mischievous person', or 
Fregger 'mischievous child' (for a full list of stimuli, see https://osf.io/n82c5/, Experiment II).

(15) a. Des is a Schlawiner.

(no modification)

b. Des is a weng a Schlawiner.

c. Des is a Schlawinerla.

d. Des is a weng a Schlawinerla.

(quantifying construction) (morphological diminutive)

(both modifiers)

Question: Auf einer Skala von 1-10, wie gerissen ist der Bürgermeister laut dieser Aussage?

'On a scale from 1-10, how cunning is the mayor according to this statement?'

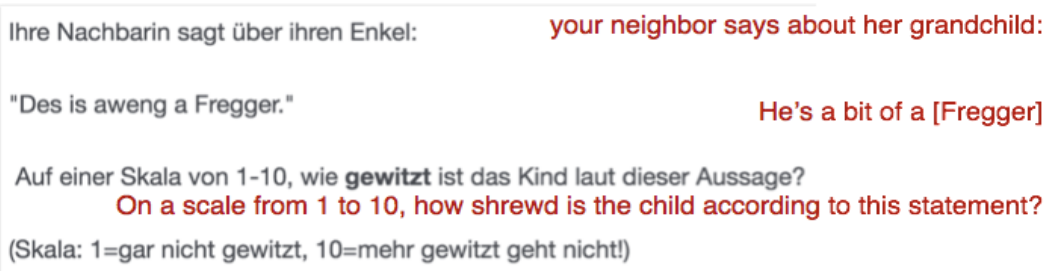

(scale: 1 = not at all shrewd, 10 = impossible to be more shrewd)

Figure 5. Evaluation task in Experiment II (unmodified condition).

In addition to the eight critical items, we also used eight fillers. Those were also gradable nouns (that is, Schnorrer 'freeloader', Dadderer 'very old man'). These were presented with a range of adjectival or adverbial modifications, but never with the modifiers under investigation. In three of the fillers, we asked for typical properties (that is, how "gesprächig" 'loquacious' a "rechda Ladschkabbm" 'a.pretty talkative.person' was). We expected relatively strong ( $50 \%$ and above) judgments for these fillers.

Since we expected stronger judgments for critical items as well, we countered the expected imbalance by also including five fillers in which we asked for the polar opposite of the scalar predicate (that is, how “freundlich" 'friendly' a "ganz a Oarlicher" 'a.very grumpy.person' was). 
As in experiment 1 , the presentation of trials was Latin-squared, such that each participant never saw a given expression more than once. Our dependent variable was the evaluation strength of adjectival descriptions (that is, gerissen 'cunning'). An example of a trial is shown in figure 5.

\subsection{Results and Discussion.}

The fillers were rated as expected: Nouns whose typical property was evaluated received average ratings between $70.7 \%$ and $88.9 \%$ (range: $4 \% \sim 100 \%$ ); nouns, for which the polar opposite of their typical property was evaluated received average ratings between $10.3 \%$ and $31.8 \%$ (range: $0 \% \sim 100 \%$ ). This again is an indication that participants understood the task, were paying attention, and used the full range of the scale.

The mean rating per critical condition and the standard error are shown in figure 6 . The overall rating patterns were analyzed using a binomial mixed effects regression on dummy-coded data (Baayen et al. 2008), implemented with R's lme4 package (Bates et al. 2014). We coded the unmodified expression as a baseline condition (no modification, the quantifying construction $a$ weng $a$, the morphological diminutive -la, or both) and location (coded as being from Hof/Rehau versus all other areas) as fixed effects, and random slopes of condition and age of participant, item, and participant (Barr et al. 2013). We also conducted planned pairwise comparisons with contrast-coded data in a binomial model using the same effects structure as for the omnibus analysis, collapsing across conditions, and Bonferroni-correcting for multiple comparisons. 


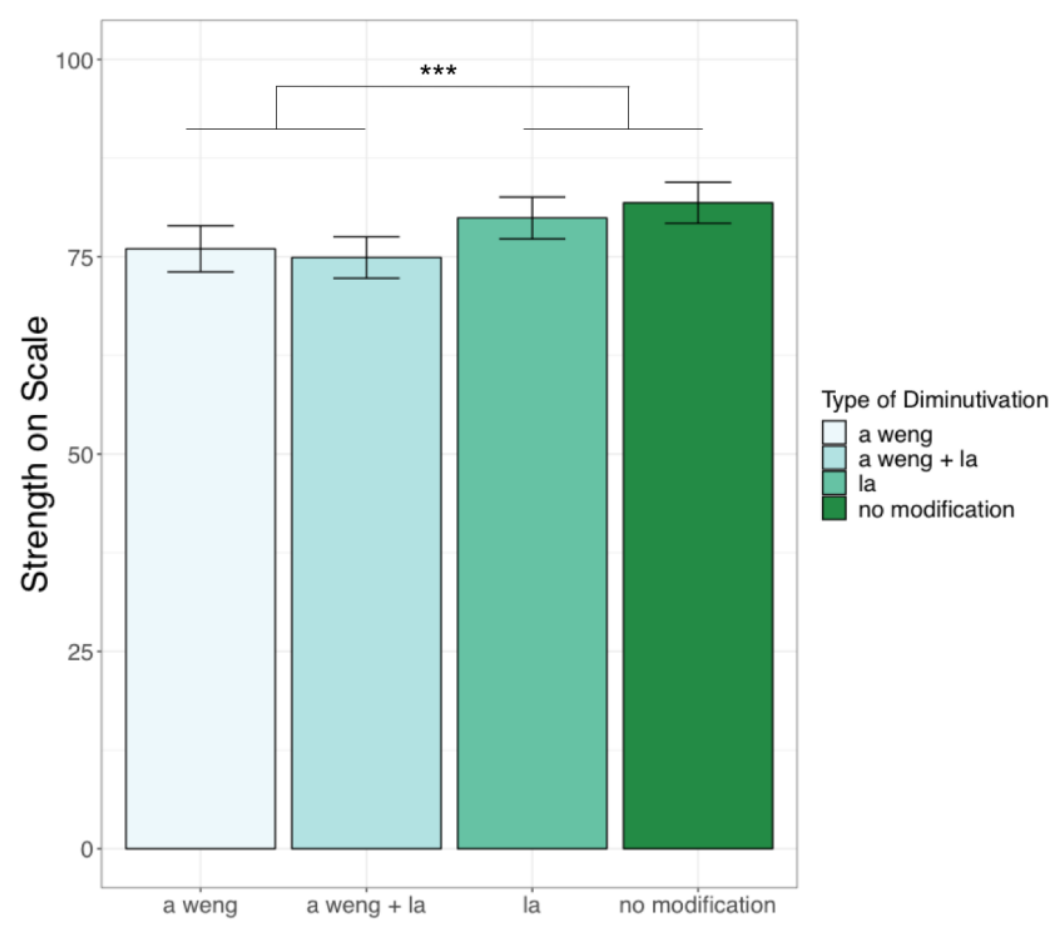

Figure 6. Mean strength ratings of gradable nouns (with SEs) in experiment 2.

As table 2 shows, Location had a significant effect on ratings: Speakers from the Hof/Rehau region of Franconia rated the expressions as stronger than people outside that region $(\beta=-0.89, p<.001)$. Crucially, as in experiment 1, the morphological diminutive (Schlawiner-la, $79.9 \%$ ) did not result in ratings different from the unmodified expression (Schlawiner, $81.8 \%$ ). However, both the quantifying construction ( $a$ weng $a$ Schlawiner, 76\%) alone, and in combination with the morpho-logical diminutive ( $a$ weng a Schlawiner-la, 74.9\%), resulted in significantly lower ratings than the unmodified expression. 


\begin{tabular}{|c|c|c|c|}
\hline Omnibus analysis: & $\beta$ & SE & $p$-value \\
\hline morphological diminutive $(-l a)$ & -0.18 & 0.41 & 0.66 \\
\hline $\begin{array}{l}\text { quantifying construction ( } a \\
\text { weng } a)\end{array}$ & -0.76 & 0.37 & 0.04 \\
\hline both ( $a$ weng a N-la) & -0.85 & 0.37 & 0.02 \\
\hline location ( \pm Rehau/Hof) & -0.89 & 0.27 & 0.00 \\
\hline \multicolumn{4}{|l|}{ Pairwise comparisons: } \\
\hline $\begin{array}{l}\text { condition }( \pm l a) \\
\text { location }( \pm \text { Rehau/Hof) }\end{array}$ & \begin{tabular}{|l|}
0.04 \\
-0.27 \\
\end{tabular} & $\begin{array}{l}1.08 \\
-2.78\end{array}$ & $\begin{array}{l}0.56 \\
0.02\end{array}$ \\
\hline $\begin{array}{l}\text { condition }( \pm a \text { weng } a) \\
\text { location }( \pm \text { Rehau/Hof) }\end{array}$ & \begin{tabular}{|l|}
0.36 \\
-0.89 \\
\end{tabular} & $\begin{array}{l}2.78 \\
-3.35\end{array}$ & $\begin{array}{l}0.02 \\
0.00\end{array}$ \\
\hline
\end{tabular}

Table 2. Results of regression analyses, experiment 2 (top: omnibus effects, bottom: planned comparisons.) Significant effects are in bold.

For both pairwise analyses, Location was again a strong predictor. More importantly, the first pairwise analysis compared ratings for conditions containing the morphological diminutive (see $15 \mathrm{c}, \mathrm{d}$ ) to the conditions not containing it (see 15a,b). Results reported in the bottom half of table 2 suggest that the presence or absence of the morphological diminutive made no difference for ratings. The second pairwise analysis compared ratings for conditions containing the quantifying construction (see 15b,d) to the conditions not containing it (see 15a,c), and the difference was highly significant. These results indicate that the presence or absence of the morphological diminutive had no effect on how strongly people rated the degree to which a predicate holds in gradable nouns but that the addition of the quantifying construction $a$ weng $a$ reduced the degree of the same predicate in gradable nouns significantly.

This study investigated the effect of the morphological diminutive $-l a$ and the quantifying construction $a$ weng $a$ on the degree semantics of gradable nouns, such as Gribbl 'crook'. Participants were instructed to rate the degree to which a predicate holds in gradable modified or unmodified nouns, such as Gribbl 'crook'. Again, the morphological diminutive -la did not significantly change the degree to which a predicate holds in a gradable noun, but we found that $a$ weng $a$ did. We also found a significant 
effect of location: Dialect speakers from the region around Rehau rate the degrees of the predicates of the gradable nouns stronger than everyone else. This is an interesting effect of dialectal microvariation onto the conceptual effects of diminutization. However, one cannot exclude two other factors that may explain this finding: First, the vast majority of our participants were from this corner of Upper Franconia, and it might be that the relative scarcity of data from other regions of Upper Franconia in the statistical model skewed the weight of this group's result. Second, this may be a familiarity effect, since both the gradable nouns and the adjectives were taken from a region-specific dialect lexicon (Müller 2013): The perceived intensity of a gradable noun may be stronger when one is more familiar with it. While the first factor is hard to control for in large-scale, citizen science experiments, the second possibility could be explored by using expressions from several dialect dictionaries, casting a wider net across the geographic distribution of lexical expressions.

\section{General Discussion.}

This paper presented two psycholinguistic experiments that studied how speakers of East Franconian perceive the semantic effect of the two diminutive devices their dialect often makes use of. In particular, we made the following predictions:

(i) both the diminutive suffix - $l a$ and the quantifying construction $a$ weng $a$ could signal that the size of the noun referent is diminished and thus function as a modifier in the conceptual domain of magnitude.

(ii) both the diminutive suffix -la and the quantifying construction $a$ weng $a$ could also potentially diminish the degree to which to which a predicate holds in gradable noun phrases.

Hypothesis i is motivated by the observation across grammars that highly frequent morphemes are often semantically bleached; given the frequency of diminutive strategies in Upper German dialects, we empirically investigated whether or not their magnitude reduction function is, indeed, available to speakers of these dialects. Hypothesis ii leans on the fact that a weng can modify degrees of predicates, like gradable adjectives, but also inherent degrees of a restricted set of nouns (see section 2.3). Given the parallel syntactic distribution of -la and $a$ weng $a$ onto count nouns in East 
Franconian (see sections 2.1 and 2.2), we investigated these hypotheses by using nongradable (experiment 1) and gradable (experiment 2) nouns. Let us briefly recap the results of these experiments.

Experiment 1 showed that in East Franconian, neither diminutive strategy-neither the morphological diminutive -la nor the quantifying construction $a$ weng $a$, nor their combination-resulted in people picking out smaller referents than when they heard the unmodified noun. We interpreted this null result as indicating that neither diminutive marker in East Franconian has any conceptual effect with regard to the magnitude (here: size) of an object: For speakers of East Franconian, a Schnitza-la is as big as a Schnitzl.

Experiment 2 demonstrated that the presence or absence of the quantifying construction $a$ weng $a$ significantly influences how strongly prople conceptualize the degree of a predicate: For speakers of East Franconian, a "Gribba-la" is just as much of a crook as a "Gribbl", but "a weng a Gribbl" has lost some of his "villain-ness".

Note that in both studies, we ascribe importance to not finding an effect of the presence of either diminutive strategy (experiment 1) or the lack of an effect of only the morphological diminutive -la (experiment 2). Interpreting null results is always a difficult problem: Perhaps our task was not sensitive enough to detect a difference, or we did not have enough statistical power. As for the question of sensitivity, it is useful to compare our task to others that investigated how linguistic magnitude information is processed. In a seminal study, Sedivy et al. (1999) asked participants to pick the small glass from a set of items. In the critical condition, the array contained two glasses, one taller than the other. Participants overwhelmingly picked the target item (the smaller glass out of the two). If the semantics of East Franconian diminutives had any magnitudeindicating function beyond marking count nouns, they should behave like gradable magnitude adjectives, and we should have found effects similar to Sedivy et al. (1999). Parzuchowski et al. (2016; Experiment 3) used a task in Polish that was very similar to ours, but which had a wider range of sizes and more trials; yet they only found an extremely small, potentially spurious, effect of diminutization, and only on a subset of items. Thus, we conclude based on our data, that if there is a real effect of diminutive strategies on the conceptualization of magnitude, it is so small as to be disregarded. 
Another potential problem with experiment 1 could have been that the relative sizes of the objects were not anchored to a scale; that is, our participants could have inferred that, in fact, only the size of the picture, but not the object itself, changed. ${ }^{5}$ This is a valid concern, and while we agree that such an anchoring to a scale or reference object would have been ideal and preferred, we again turn to extant literature: Parzuchowski et al.'s (2016) Experiment 3 detached picture size from object size by using photographs of different-sized objects in the same box. Yet again, their experiment only found very small effects. We hope that future studies follow Parzuchowski et al. (2016) design decision.

Of course, this does not exclude the second possibility mentioned above, that the lack of effect is due to small statistical power. Since we did not have any prior expectations about how big of an effect we should see if it existed, we could not run a power analysis to exclude this possibility. However, we did collect 248 data points per condition, from 124 participants. The number of experimental items was intentionally kept small to prevent boredom and increase the likelihood of people finishing the experiment. Indeed, we by no means obtained a small sample size, especially considering that we are investigating a relatively small language - for instance, almost $2 \%$ of the population of Rehau (the city whose dialect dictionary we used to create items in experiment 2 , that is, Müller 2013) participated in our studies. For comparison, if one wanted to include in an experiment data from $2 \%$ of Standard German speakers, one would have to test 1.6 million participants. This is not a statistical argument, of course, but a consequence of studying languages smaller than standard varieties with volunteer subjects. In addition, the fact that we did find a robust difference in experiment 2 for the presence and absence of $a$ weng a suggests that the study was sufficiently powered.

As for comparative linguistic work, our paper contributes to a vast crosslinguistic literature on diminutive strategies that analyzes them as multifaceted instruments of linguistic expression. They can function as semantic markers of magnitude (see, among others, Jurafsky 1996, Schneider 2013), and they function as syntactic markers of count nouns, as well as triggers of a variety of pragmatic inferences, from politeness to hedging (Mendoza 2005, Ogiermann 2009).

\footnotetext{
${ }^{5}$ Thanks to an anonymous reviewer who pointed out this possibility.
} 
According to the literature, East Franconian diminutive strategies can also have some of these nonliteral effects, and, for instance, mean the opposite of 'a little'. For example, a weng a Schdindla lit. 'a little bit of an hour' denotes more than one hour (Schiepek 1908, Kolmer 1999). Comparable semantic shifts can also be found in Standard German or English, for example when (He is) not very nice is interpreted as an in fact stronger version of (He is) not nice (see Leffel et al. 2019).

In addition, there is no question that diminutives in East Franconian, above and beyond any semantic effects, realize similar metric constraints as diminutives in Standard German (Wiese 2006, Edelhoff 2016). As Edelhoff (2016) similarly observes for other nonstandard varieties such as Luxembourgish, the preferred lexical meter in East Franconian seems to be dactylic, not trochaic: A monosyllabic noun containing a short vowel, such as Depp 'idiot', will be Depp-er-la under diminutization in East Franconian; monosyllabic nouns containing a long vowel, such as Baam 'tree', are acceptable in both trochaic (Baam-la) and dactylic (Baam-a-la) form, with a slight preference for the latter. The contribution of diminutives to overall metric and prosodic structure in East Franconian is therefore consistent with that of diminutives in other languages and varieties and would certainly be a fruitful topic for further research.

Above and beyond those functions however, in our paper, we started with an observation about diminutives as realizing the basic conceptual function of individuation (Jurafsky 1996). This allowed us to compare further conceptual effects of both the morphological realization of this individuation function (the suffix $-l a$ ), and a phrase-level realization ( $a$ weng a). Also, we did not take it for granted that diminutive strategies in Upper German varieties have additional functions (such as reducing sizes of objects) because their high frequency may correspond to a rather poor (bleached) semantics. The frequency of the morphological diminutive in East Franconian may be the culprit for this lack of effect on conceptualization. Crosslinguistically, we might predict that in languages where diminutives are used sparingly and mainly in informal contexts, such as child-directed speech in English (for example, doggie versus dog; Burnham et al. 2002), those uses have a stronger pragmatic effect than in languages that use diminutives frequently and in both formal and informal settings.

Indeed, our results suggest that in East Franconian, the morpho-logical diminutive is restricted to the individuation function, but $a$ weng $a$ can 
operate on degrees and reduce their strength. From a phrase-structural point of view, this would be expected because the morphological diminutive is a numeral classifier inside the noun phrase (see our phrasestructural discussion in section 2.1 above), while the complex expression $a$ weng $a$ operates at the higher phrase-structural level of the determiner (the so-called extended noun phrase) and could thus potentially modify the referential possibilities (including the extent to which a predicate of the noun holds; see section 2.2). In other words, $a$ weng $a$ can take scope over the noun phrase, while the suffix is attached at a structural level much lower. Semantically, the effect of $a$ weng $a$ is likewise expected because the parallels between quantifying mass nouns and measuring degrees have long been noted (see, among others, Wellwood 2015), and weng usually functions as a mass noun quantifier.

We want to conclude with a point about the methodological approach we took, relying heavily on the involvement of local media to advertise for this research project. This was necessary to gather data in the first place (see Rodd et al. 2016 for an ingenious larger-scale use of this strategy). However, by now the studies' main finding, translated into laymen's terms - that East Franconians understand $a$ weng $a$ to reduce the strength of a word such as Gribbl - has been broadcast publicly in two radio interviews, one local and one regional. ${ }^{6}$ This approach, of course, prohibits close follow-up experiments on diminutization, since now a sizeable part of the community potentially knows about the aim of the study. However, we did this on purpose in order to foster 'participatory citizen science' (for example, Kimura \& Kinchy 2016): We do not use citizens as mere subjects in our studies, useful to draw data from and uninteresting beyond that. Instead, through our research and its dissemination, we aim to build linguistic awareness, foster positive language attitude, and create a community of engaged speakers and responsible researchers. Ideally, this approach can contribute to slowing down the creeping death of dialects and revitalize linguistic diversity.

\footnotetext{
${ }^{6}$ See, for example, https://soundcloud.com/extra-radio/prof-dr-eva-wittenberg; https://www.frankenpost.de/region/rehau/Ich-finde-Rehauerischklasse;art2452,6380238
} 


\section{REFERENCES}

Baayen, R. Harald, Douglas J. Davidson, \& Douglas M. Bates. 2008. Mixedeffects modeling with crossed random effects for subjects and items. Journal of Memory and Language 59.390-412.

Bale, Alan, \& David Barner. 2009. The interpretation of functional heads: Using comparatives to explore the mass/count distinction. Journal of Semantics 26. 217-252.

Bale, Alan, \& David Barner. 2018. Quantity judgment and the mass-count distinction across languages: Advances, problems, and future directions for research. Glossa: A Journal of General Linguistics 3. 63. http://doi.org/10.5334/gjgl.536.

Barr, Dale J., Roger Levy, Christoph Scheepers, \& Harry J. Tily. 2013. Random effects structure for confirmatory hypothesis testing: Keep it maximal. Journal of Memory and Language 68. 255-278.

Bates, Douglas M., Martin Maechler, Ben Bolker, Steven Walker, Rune Haubo Bojesen Christensen, Henrik Singmann, Bin Dai, \& Fabian Scheipl, Rcpp, L. 2014. Package 'Ime4'. Vienna: R Foundation for Statistical Computing.

Brandner, Ellen. 2008. Patterns of doubling in Alemannic. Microvariation in syntactic doubling, ed. by Sjef Barbiers, Olaf Koeneman, Marika Lekakou, \& Margreet van der Ham, 353-379. Bingley: Emerald.

Burnham, Denis, Christine Kitamura, \& Uté Vollmer-Conna. 2002. What's new pussycat? On talking to babies and animals. Science 296. 1435.

Christensen, Rune Haubo Bojesen. 2019. Ordinal—Regression models for ordinal data. R package version 2019.12-10. Available at http://www.cran.rproject.org/package $=$ ordinal/

Dressler, Wolfgang U., \& Lavinia M. Barbaresi. 1994. Morphopragmatics: Diminutives and intensifiers in Italian, German, and other languages. Berlin: Walter de Gruyter.

Eberhard, David M., Gary F. Simons, \& Charles D. Fennig (eds.). 2015. Ethnologue: Languages of the World. 18th edn. Dallas, TX: SIL International. Available at http://www.ethnologue.com.

Edelhoff, Maike. 2016. Von Blätterchen und Bäumchen: Die Entwicklung der Plural-Diminutive und Diminutiv Plurale im Deutschen und Luxemburgischen. Wortbildung im Deutschen: Aktuelle Perspektiven, ed. by Elke Hentschel, 191-213. Tübingen: Narr Francke Attempto Verlag.

Fortin, Antonio. 2011. The morphology and semantics of expressive affixes. Oxford, UK: University of Oxford dissertation.

Hiraiwa, Ken. 2016. NP-ellipsis: A comparative syntax of Japanese and Okinawan. Natural Language \& Linguistic Theory 34. 1345-1387. Hiraiwa, Ken. 2018. Something visible in Japanese. Glossa: A Journal of General Linguistics 3. 132. http://doi.org/10.5334/gjgl.361. 
Hopper, Paul J., \& Elizabeth Closs Traugott. 2003. Grammaticalization. Cambridge: Cambridge University Press.

Jurafsky, Daniel. 1996. Universal tendencies in the semantics of the diminutive. Language 72. 533-578.

Kallulli, Dalina, \& Antonia Rothmayr. 2008. The syntax and semantics of indefinite determiner doubling constructions in varieties in German. Journal of Comparative Germanic Linguistics 11. 95-136.

Kargl, Johann. 1976. Die Verkleinerungsformen in den Mundarten von Niederbayern und Oberpfalz. Verhandlungen des Historischen Vereins für Oberpfalz und Regensburg 116. 227-250.

Kennedy, Christopher, \& Louise McNally. 2005. Scale structure, degree modification, and the semantics of gradable predicates. Language 81. 345-381.

Kimura, Aya H., \& Abby Kinchy. 2016. Citizen science: Probing the virtues and contexts of participatory research. Engaging Science, Technology, and Society 2. 331-361.

Kishimoto, Hideki. 2000. Indefinite pronouns and overt N-raising. Linguistic Inquiry 31. 557-566.

Kolmer, Agnes. 1999. Zur MASS/COUNT-Distinktion im Bairischen: Artikel und Quantifizierung (Arbeitspapier 34). Köln: Institut für Sprachwissenschaft, Universität zu Köln.

Leeuw, Joshua R. de 2015. jsPsych: A JavaScript library for creating behavioral experiments in a Web browser. Behavior Research Methods 47, 1-12.

Leffel, Timothy, Alexandre Cremers, Nicole Gotzner, \& Jacopo Romoli. 2019. Vagueness in implicature: The case of modified adjectives. Journal of Semantics 36. 317-348.

Leu, Thomas. 2008. The internal syntax of determiners. New York, NY: New York University dissertation.

Leu, Thomas. 2015. The architecture of determiners. Oxford: Oxford University Press.

Levy, Roger. 2014. Using R formulae to test for main effects in the presence of higher-order interactions. arXiv.org, Cornell University: arXiv:stat.ME/1405.2094v1.

Marantz, Alec. 1997. No escape from syntax: Don't try morphological analysis in the privacy of your own lexicon. UPenn Working Papers in Linguistics 4. 201-225.

Mendoza, Martha. 2005. Polite diminutives in Spanish. Broadening the horizon of linguistic politeness, ed. by Robin T. Lakoff \& Sachiko Ide, 163-173. Amsterdam: John Benjamins.

Morzycki, Marcin. 2009. Degree modification of gradable nouns: Size adjectives and adnominal degree morphemes. Natural Language Semantics 17. 175-203. 
Morzycki, Marcin. 2016. Modification. Cambridge: Cambridge University Press.

Müller, Hartmut. 2013. Kleines Rehauer Wörterbuch. Burg Verlag Rehau.

Ogiermann, Eva. 2009. Politeness and in-directness across cultures: A comparison of English, German, Polish and Russian requests. Journal of Politeness Research 5. 189-216.

Ott, Dennis. 2011. Diminutive-formation in German Spelling out the classifier analysis. Journal of Comparative Germanic Linguistics 14. 1-46.

Parzuchowski, Michal, Konrad Bocian, \& Pascal Gygax. 2016. Sizing up objects: The effect of diminutive forms on positive mood, value, and size judgments. Frontiers in Psychology. https://doi.org/10.3389/fpsyg.2016.01452, September 23, 2016.

Roberts, Ian. 2010. Grammaticalization, the clausal hierarchy, and semantic bleaching. Gradience, gradualness, and grammaticalization, ed. by Graeme Trousdale \& Elizabeth Closs Traugott, 45-73. Amsterdam: John Benjamins.

Rodd, Jennifer M., Zhenguang G. Cai, Hannah N. Betts, Betsy Hanby, Catherine Hutchinson, \& Aviva Adler. 2016. The impact of recent and long-term experience on access to word meanings: Evidence from large-scale internetbased experiments. Journal of Memory and Language 87. 16-37.

Schiepek, Josef. 1908. Der Satzbau der Egerländer Mundart. Zweiter Teil. Prag: Verlag des Vereines für Geschichte der Deutschen in Böhmen.

Schirmunski, Viktor M. 1962. Deutsche Mundartkunde: Vergleichende Lautund Formenlehre der deutschen Mundarten. Berlin: Akademie Verlag.

Schneider, Klaus P. 2013. The truth about diminutives, and how we can find it: Some theoretical and methodological considerations. SKASE Journal of Theoretical Linguistics 10. 137-151.

Sedivy, Julie C., Michael K. Tanenhaus, Craig G. Chambers, \& Gregory N. Carlson. 1999. Achieving incremental semantic interpretation through contextual representation. Cognition 71. 109-147.

Siebenhaar, Beat, \& Alfred Wyler. 1997. Dialekt und Hochsprache in der deutschsprachigen Schweiz. Zürich: Edition "Pro Helvetia", DokumentationInformation-Presse. Online preprint of the 5th edn., completely revised.

Wellwood, Alexis. 2015. On the semantics of comparison across categories. Linguistics and Philosophy 38. 67-101.

Wiese, Heike. 2006. Partikeldiminuierung im Deutschen. Sprachwissenschaft 31. 457-489.

Wiese, Heike, \& Joan Maling. 2005. Beers, kaffi, and Schnaps: Different grammatical options for 'restaurant talk' coercions in three Germanic languages. Journal of Germanic Linguistics 17. 1-38.

Wiltschko, Martina. 2006. Why should diminutives count? Organizing Grammar: Studies in Honor of Henk van Riemsdijk, ed. by Hans Broekhuis, 
Norbert Corver, Riny Huybregts, Ursula Kleinhenz, \& Jan Koster, 669-679. Berlin: Mouton de Gruyter.

Wittenberg, Eva, \& Roger Levy. 2017. If you want a quick kiss, make it count: How choice of syntactic construction affects event construal. Journal of Memory and Language 94. 254-271.

Eva Wittenberg

Department of Cognitive Science

Central European University

Quellenstr. 51

1110 Wien

Austria

[wittenberg@ceu.edu]

Andreas Trotzke

Department of Linguistics

University of Konstanz

Universitätsstraße 10

78457 Konstanz

Germany

[andreas.trotzke@uni-konstanz.de] 